\title{
Study of a Magnetooptic Contact for an Amplifying Waveguide Optical Isolator
}

\author{
Wouter Van Parys, Student Member, IEEE, Mathias Vanwolleghem, Dries Van Thourhout, Member, IEEE, \\ Roel Baets, Fellow, IEEE, Francois Lelarge, Bruno Thedrez, and Liesbet Lagae
}

\begin{abstract}
We report on the development of an ohmic metal-semiconductor contact for application in an amplifying waveguide optical isolator. It is the result of magnetooptic waveguide simulations combined with experimental extraction of the contact resistivity. The optimized contact scheme is a $\mathbf{p}^{++}$-doped hybrid $\mathrm{In}_{0.81} \mathrm{Ga}_{0.19} \mathrm{As}_{0.41} \mathrm{P}_{0.59}-\mathrm{In}_{0.53} \mathrm{Ga}_{0.47} \mathrm{As}$ structure, a compromise between good isolating performance and good electrical behavior.
\end{abstract}

Index Terms-Magnetooptic (MO) Kerr effect, ohmic electrical contact, optical isolator.

\section{INTRODUCTION}

A $\mathrm{N}$ OPTICAL isolator is indispensable in a telecom link to protect laser sources against back-reflected light. A waveguide version of this component is highly desirable as it would decrease the packaging cost—hence the overall cost—of a laser diode module largely. An approach that is getting a lot of attention in recent years [1], [2] involves the use of a ferromagnetic metal as the source of the nonreciprocal effect. In an optical waveguide covered with a transversely magnetized ferromagnetic metal film close to the guiding region, the magnetooptic (MO) Kerr effect induces a nonreciprocal shift of the complex effective index of the guided mode. Consequently, the modal loss is dependent on the propagation direction of the light. If the guiding core consists of amplifying layers, electrical biasing decreases the internal loss of the waveguide. The result is a device which, being transparent in the forward while providing loss in the opposite direction, is isolating. As the isolator basically has the same structure as the laser it is to be integrated with, monolithic integration is straightforward. In the simplest configuration, illustrated in Fig. 1 and operating for transverse magnetic (TM) polarized light, the ferromagnetic metal acts as the electrical contact for the underlying semiconductor optical amplifier. This letter presents the important issue of the development of an ohmic electrical contact for application in this optical isolator. We show that a compromise needs to be made between good optical and MO performance and good electrical behavior.

Manuscript received September 22, 2006; revised Febuary 14, 2007. This work has been carried out in the framework of the IST-ISOLASER Project.

W. Van Parys, D. Van Thourhout, and R. Baets are with the Photonics Research Group, Department of Information Technology (INTEC), Ghent University-IMEC, B-9000 Gent, Belgium (e-mail: Wouter.VanParys@ intec.UGent. be).

M. Vanwolleghem is with the Institut d'Electronique Fondamentale, Université Paris-Sud, 91405 Orsay Cedex, France.

F. Lelarge is with the Alcatel Thales III-V Laboratory, 91767 Palaiseau, France.

B. Thedrez is with the Département COMELEC, ENST, 75634 Paris, Cedex 13, France.

L. Lagae is with IMEC vzw, B-3001 Leuven, Belgium.

Digital Object Identifier 10.1109/LPT.2007.894965

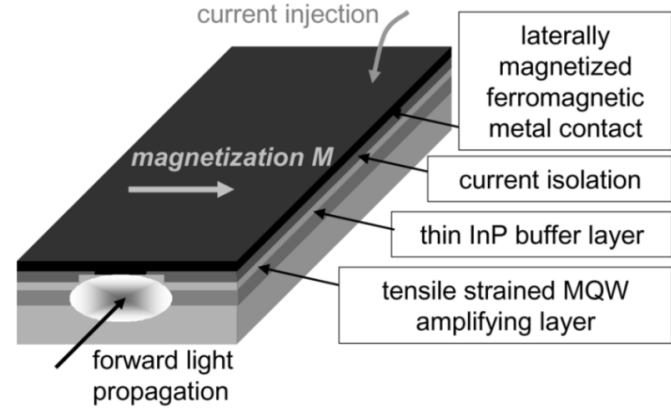

Fig. 1. Schematic layout of the TM-mode amplifying waveguide optical isolator

\section{THEORY}

The physical parameter that describes the quality of a metal-semiconductor contact is the contact resistivity $\rho_{c}$, defined as

$$
\rho_{c}=\left[\frac{\partial J}{\partial V}\right]_{V=0}^{-1}=\frac{k T}{q J_{s}}
$$

with $J$ the current density and $V$ the voltage across the contact, $J_{s}$ the saturation current of the semiconductor-metal contact, $k$ the Boltzmann constant, $T$ the temperature and $q$ the electron charge. If the contact resistivity is low (order $\left.10^{-5} \Omega \cdot \mathrm{cm}^{2}\right)$-or equivalent the saturation current high-implying that the contacted device is not substantially influenced by the metal-semiconductor contact, the contact is said to be ohmic. The saturation current increases with diminishing barrier height between metal and semiconductor and with increasing dopant levels of the semiconductor layer in contact with the metal. The latter is due to the increase of the tunneling current contribution to the saturation current. Due to pinning of the Fermi level in III-V semiconductors [3], the barrier height and consequently the contact resistivity are quasi-independent of the work function of the metal, hence, the unusual choice of the contact metal - a ferromagnetic metal-is not expected to deteriorate the contact quality. Furthermore, as one can expect that the p-barrier height is about one third of the bandgap energy [4], a semiconductor contact material with small bandgap is preferable for an ohmic electrical contact. The material lattice-matched to InP with the lowest bandgap is $\mathrm{In}_{0.53} \mathrm{Ga}_{0.47} \mathrm{As}$, hence the standard electrical contact of an amplifying device is composed of a highly doped $\mathrm{In}_{0.53} \mathrm{Ga}_{0.47}$ As layer (100-150 nm thick) between the cladding and the metal. For the amplifying waveguide isolator the situation is more complicated. As the isolator performance is determined by the overlap of the guided mode with the ferromagnetic metal, it is essential that the semiconductor contact 
structure absorbs as little as possible. Therefore, with the complex refractive index of $\operatorname{In}_{0.53} \mathrm{Ga}_{0.47}$ As $n-j k=3.6-j 0.207$ [5] at 1300-nm wavelength, a standard contact is not suitable for the isolator. Instead we propose a contact scheme consisting of an $\mathrm{In}_{0.81} \mathrm{Ga}_{0.19} \mathrm{As}_{0.41} \mathrm{P}_{0.59}$ layer topped with a (thin) $\mathrm{In}_{0.53} \mathrm{Ga}_{0.47}$ As layer, both heavily doped. The absorption of $\operatorname{In}_{0.81} \mathrm{Ga}_{0.19} \mathrm{As}_{0.41} \mathrm{P}_{0.59}$ at $1300 \mathrm{~nm}$ is low compared to $\mathrm{In}_{0.53} \mathrm{Ga}_{0.47} \mathrm{As}: n-j k=3.37-j 0.0027$ [5], [6], including the absorption due to the high doping $\left(N=2 \times 10^{19} \mathrm{~cm}^{-3}\right)$. This letter discusses what the thickness of these layers must be to obtain an ohmic contact for the amplifying waveguide isolator.

\section{OPTIMIZATION OF THE MO CONTACT}

The influence of the contact scheme on the (magneto)-optical performance is determined through simulation of an isolator benchmark example with a variety of $\mathrm{In}_{0.53} \mathrm{Ga}_{0.47} \mathrm{As}$ and $\mathrm{In}_{0.81} \mathrm{Ga}_{0.19} \mathrm{As}_{0.41} \mathrm{P}_{0.59}$ layer thicknesses. The isolator is an AlGaInAs-InP multiple quantum-well heterostructure with a 400-nm InP cladding layer [1]. The ferromagnetic metal is a 50-nm $\mathrm{Co}_{50} \mathrm{Fe}_{50}$ film. Among the three $\mathrm{Co}_{x} \mathrm{Fe}_{1-x}$ compounds that have been experimentally characterized $\left(\mathrm{Co}_{90} \mathrm{Fe}_{10}\right.$, $\mathrm{Co}_{50} \mathrm{Fe}_{50}$, and $\mathrm{Fe}$ ), $\mathrm{Co}_{50} \mathrm{Fe}_{50}$ was found to be the best compromise between high MO effect and low absorption [7]. Calculations have been done with the mode solver CAMFR [8] extended with a perturbation algorithm for MO waveguide calculation. The experimental values of the optical and MO parameters of $\mathrm{Co}_{50} \mathrm{Fe}_{50}$ [7] served as input.

The relevant figure of merit (FoM) for the study of the MO contact is the ratio between the nonreciprocal loss shift $\Delta \alpha$ and the remaining loss in the forward propagation direction, the "isolation-to-loss ratio." The loss obviously increases monotonously with increasing thickness of the absorbing $\mathrm{In}_{0.53} \mathrm{Ga}_{0.47}$ As layer. The nonreciprocal loss shift $\Delta \alpha$ is calculated with the perturbation formula developed in [7]

$$
\Delta \alpha=\frac{|g|\left|E_{x}\left(x_{m+}\right)\right|^{2}}{Z_{\mathrm{vac}}\left|n_{\mathrm{eff}}\right|} \sin \left(\angle g+2 \angle E_{x}\left(x_{m+}\right)\right)
$$

with $g$ the complex gyro-electric constant of the ferromagnetic metal, $Z_{\mathrm{vac}}$ the vacuum impedance, $E_{x}\left(x_{m+}\right)$ the transverse electric field component at the semiconductor-metal interface, and $n_{\text {eff }}$ the effective index of the TM-guided mode of the waveguide device. With the complex argument of $g$ for $\mathrm{Co}_{50} \mathrm{Fe}_{50}$ equal to $(-\pi / 4), \Delta \alpha$ is maximal if the complex argument of $E_{x}\left(x_{m+}\right)$ equals $(3 \pi / 8)+p(\pi / 2)$, with $p$ an integer. In Fig. 2, the simulated absolute value of $\sin \left(\angle g+2 \angle E_{x}\left(x_{m+}\right)\right)$ (2) is plotted as a function of the two contact layer thicknesses. Variation of these layers clearly allows for tuning of the phase of the transverse electric field component $E_{x}\left(x_{m+}\right)$. Every thickness of the absorbing layer below $80 \mathrm{~nm}$ has a corresponding quasi-transparent layer thickness that maximizes the sine factor and consequently the nonreciprocal loss shift $\Delta \alpha$. For absorbing layer thickness values of a few tens of nanometers-the range important for the amplifying waveguide isolator-the sine factor can be considered to saturate at the value of one with increasing quasi-transparent layer thickness, at least up to $200 \mathrm{~nm}$. Maximizing $\Delta \alpha$ is, therefore, a matter of choosing the quasi-transparent contact layer "thick enough."

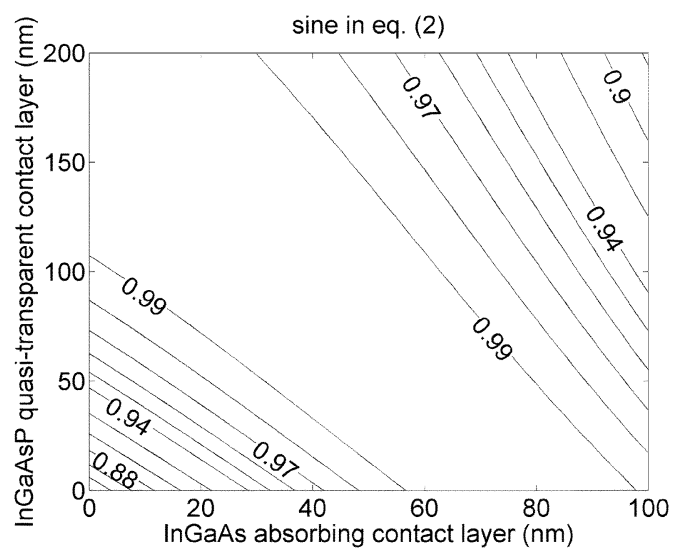

Fig. 2. Simulated evolution of $\sin \left(\angle g+2 \angle E_{x}\left(x_{m+}\right)\right)$ (2) with variation of the InGaAs absorbing and InGaAsP quasi-transparent layer thickness.

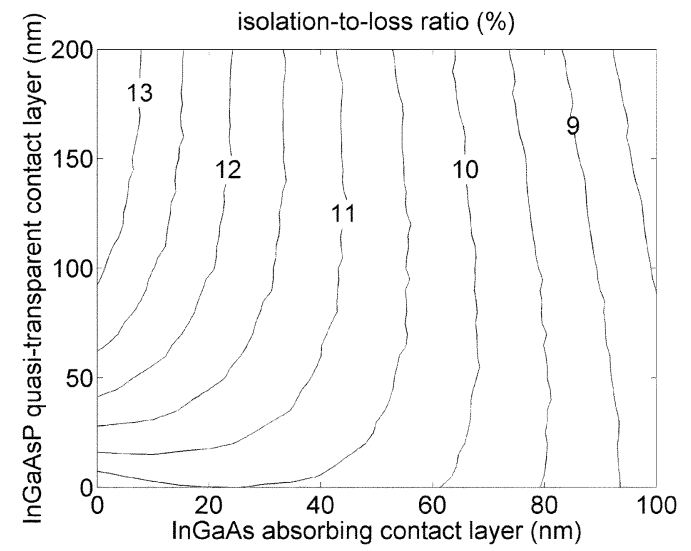

Fig. 3. Simulated evolution of the isolation-to-loss ratio (in percent) with variation of the InGaAs absorbing and InGaAsP quasi-transparent layer thickness.

TABLE I

SPECIFICATIONS OF THE STUDIED CONTACT SCHEMES

\begin{tabular}{|ccc|}
\hline label & composition & thickness $(\mathrm{nm})$ \\
\hline \hline $\mathrm{T}$ & $\mathrm{In}_{0.53} \mathrm{Ga}_{0.47} \mathrm{As}$ & 100 \\
\hline $\mathrm{H} 1$ & $\mathrm{In}_{0.81} \mathrm{Ga}_{0.19} \mathrm{As}_{0.41} \mathrm{P}_{0.59} / \mathrm{In}_{0.53} \mathrm{Ga}_{0.47} \mathrm{As}$ & $100 / 15$ \\
\hline $\mathrm{H} 2$ & $\mathrm{In}_{0.81} \mathrm{Ga}_{0.19} \mathrm{As}_{0.41} \mathrm{P}_{0.59} / \mathrm{In}_{0.53} \mathrm{Ga}_{0.47} \mathrm{As}$ & $100 / 5$ \\
\hline $\mathrm{Q} 1$ & $\mathrm{In}_{0.81} \mathrm{Ga}_{0.19} \mathrm{As}_{0.41} \mathrm{P}_{0.59}$ & 100 \\
\hline $\mathrm{Q} 2$ & $\mathrm{In}_{0.81} \mathrm{Ga}_{0.19} \mathrm{As}_{0.41} \mathrm{P}_{0.59}$ & 50 \\
\hline
\end{tabular}

It is now straightforward to understand the evolution of the isolation-to-loss ratio with variation of the contact layer thicknesses, as plotted in Fig. 3. The isolation-to-loss ratio is maximized by minimizing the absorbing layer and by choosing a thickness combination that maximizes the sine factor that determines $\Delta \alpha$ (2). As such, a "thick," quaternary contact gives the highest (magneto)-optical performance.

\section{EXPERIMENTAL EXTRACTION OF THE CONTACT RESISTIVITY}

As explained before, the electrical quality of the metal-semiconductor contact increases with decreasing bandgap energy of the semiconductor in contact with the metal; hence, from the electrical point of view, a quaternary contact might not be preferred. The contact resistivity of five contact schemes with different thicknesses of the absorbing ternary and quasi-transparent quaternary layer has been measured (Table I): 


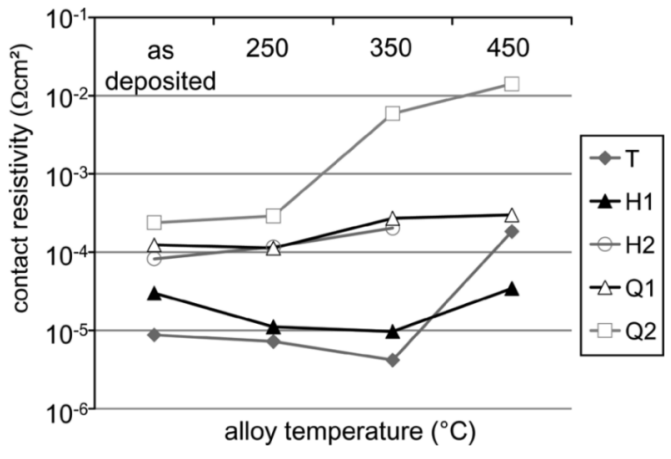

Fig. 4. Experimentally extracted contact resistivity for different RTP temperatures, for all five contact structures under study.

a reference ternary sample $(T)$, two quaternary structures $(Q 1$ and $Q 2)$, and two hybrid schemes ( $H 1$ and $H 2)$ with a "thick" quaternary layer topped with a "thin" ternary layer.

For the extraction of the electrical quality of the five contact structures, cross-bridge Kelvin resistors (CBKR) have been fabricated. Among all types of test structures, the CBKR provides the best compromise between ease of extraction and sensitivity to parasitic current crowding effects, at least when aided with 2-D numerical simulations [9]. In a 2-D model of the test structure, the voltage $(V)$ distribution is described by

$$
\nabla_{t}^{2} V=\frac{V R_{s}}{\rho_{c}}
$$

with $R_{s}$ the sheet resistance of the semiconductor layer. Solving this boundary value problem with a MATLAB algorithm enables very accurate extraction of the contact resistivity. Our numeric tool takes into account the influence of possible processing imperfections such as misalignment of the lithography mask and underetching of the semiconductor mesa.

The $\quad \mathrm{Be} \quad \mathrm{p}^{++}$-doped $\mathrm{In}_{0.81} \mathrm{Ga}_{0.19} \mathrm{As}_{0.41} \mathrm{P}_{0.59}$ $\left(\mathrm{N}_{\mathrm{Be}}=2 \times 10^{19} \mathrm{~cm}^{-3}\right)$ and $\mathrm{In}_{0.53} \mathrm{Ga}_{0.47} \mathrm{As}$ $\left(\mathrm{N}_{\mathrm{Be}}=3 \times 10^{19} \mathrm{~cm}^{-3}\right)$ layers have been grown using gas source molecular beam epitaxy (GSMBE) on an InP substrate. Whereas such high dopant levels are standard for $\mathrm{In}_{0.53} \mathrm{Ga}_{0.47} \mathrm{As}$, this is not the case for $\mathrm{In}_{0.81} \mathrm{Ga}_{0.19} \mathrm{As}_{0.41} \mathrm{P}_{0.59}$. The high dopant concentration could be achieved by growing the quaternary material at low temperature $\left(T_{s}=460^{\circ} \mathrm{C}\right)$. A 50-nm-thick $\mathrm{Co}_{50} \mathrm{Fe}_{50} \mathrm{MO}$ metal layer was sputtered and topped with a Ti-Au protective bilayer $(40 \mathrm{~nm} / 150 \mathrm{~nm})$. Rapid thermal processing (RTP), which is known to improve the contact quality [10], was carried out at $250^{\circ} \mathrm{C}, 350^{\circ} \mathrm{C}$, and $450^{\circ} \mathrm{C}$, in a forming gas ( $\left.\mathrm{N} 2: \mathrm{H} 2\right)$ atmosphere (duration, $30 \mathrm{~s}$ ).

As is illustrated in Fig. 4, a quaternary contact $(Q 1$ and $Q 2$ ) has a contact resistivity beyond the acceptable value, but the quality of a standard electrical contact ( $T$ scheme) can be well approached by topping a $100-\mathrm{nm} \mathrm{In}_{0.81} \mathrm{Ga}_{0.19} \mathrm{As}_{0.41} \mathrm{P}_{0.59}$ layer with a $15-\mathrm{nm} \operatorname{In}_{0.53} \mathrm{Ga}_{0.47} \mathrm{As}$ layer ( $H 1$ scheme) and performing RTP at $350^{\circ} \mathrm{C}\left(\rho_{c, H 1}=10^{-5} \Omega \cdot \mathrm{cm}^{2}\right)$.

\section{Simulation of the IsOlator PERformance}

In Table II, the calculated values of the isolation-to-loss ratio for the five contact schemes are given, showing that the (magneto)-optical performance of the $\mathrm{H} 1$ scheme is $39 \%$ better than that of the standard ternary contact.
TABLE II

Simulated IsOlator PerformanCE FOR THE Five CONTACT SCHEMES

\begin{tabular}{|cccc|}
\hline label & $\begin{array}{c}\text { isolation-to } \\
\text { loss-ratio }(\%)\end{array}$ & $\begin{array}{c}\text { transparency } \\
\text { current }(\mathrm{mA} / \mathrm{dB})\end{array}$ & $\begin{array}{c}\text { length } \\
(\mu \mathrm{m} / \mathrm{dB})\end{array}$ \\
\hline \hline $\mathrm{T}$ & 8.8 & 9.42 & 327 \\
\hline $\mathrm{H} 1$ & 12.2 & 6.76 & 238 \\
\hline $\mathrm{H} 2$ & 12.8 & 6.50 & 225 \\
\hline $\mathrm{Q} 1$ & 13.1 & 6.38 & 218 \\
\hline Q2 & 12.2 & 6.88 & 239 \\
\hline
\end{tabular}

The parameters determining the practical performance of the isolator are the forward transparency current and the cavity length both per unit (decibels) of optical isolation. The impact of using the hybrid contact scheme is evaluated by calculating these parameters at the optimized isolator cladding thickness for each of the five contact schemes, using minimal transparency current as the optimization FoM. As shown in Table II $(2-\mu \mathrm{m}$ ridge width), an isolator with the hybrid $H 1$ contact scheme performs more than $37 \%$ better than with the standard contact $T$ and less than $10 \%$ worse than with the best (magneto)-optical scheme $Q 1$ (omitting the electrical quality).

\section{CONCLUSION}

A standard ternary electrical contact leads to unacceptably high losses in an amplifying waveguide optical isolator, hence the development of a suitable contact scheme is highly important. From (magneto)-optical point of view, a quasi-transparent quaternary contact is preferred, but this does not result in an ohmic contact. By appropriately combining ternary and quaternary layers, we designed a contact scheme with an electrical quality similar to a standard contact with only minimal decrease in (magneto)-optical performance.

\section{REFERENCES}

[1] W. Van Parys, B. Moeyersoon, D. Van Thourhout, R. Baets, M. Vanwolleghem, B. Dagens, J. Decobert, O. Le Gouezigou, D. Make, R. Vanheertum, and L. Lagae, "Transverse magnetic mode nonreciprocal propagation in an amplifying waveguide optical isolator," Appl. Phys. Lett., vol. 88, pp. 071115-071115, 2006.

[2] H. Shimizu and Y. Nakano, "Fabrication and characterization of an InGaAsP/InP active waveguide optical isolator with $14.7 \mathrm{~dB} / \mathrm{mm}$ TE mode nonreciprocal attenuation," J. Lightw. Technol., vol. 24, no. 1, pp. 38-43, Jan. 2006.

[3] S. Kurtin, T. C. McGill, and C. A. Mead, "Fundamental transition in electronic nature of solids," Phys. Rev. Lett., vol. 22, pp. 1433-1436, 1969.

[4] C. A. Mead and W. G. Spitzer, "Fermi-level position at metal-semiconductor interfaces," Phys. Rev., vol. 134, pp. A713-A716, 1964.

[5] B. Jensen, Handbook of Optical Constants of Solids II, E. Palik, Ed. New York: Academic, 1991, pp. 125-149.

[6] A. Sneh and C. R. Doerr, Integrated Optical Circuits and Components, E. J. Murphy, Ed. New York: Marcel Dekker, 1999, p. 164.

[7] M. Vanwolleghem, W. Van Parys, P. Gogol, P. Beauvillain, and R. Baets, "Design and optimization of a monolithically integrated InPbased optical waveguide isolator," J. Opt. Soc. Amer. B, vol. 24, pp. 94-105, 2007.

[8] P. Bienstman and R. Baets, "Optical modelling of photonic crystals and VCSELs using eigenmode expansion and perfectly matched layers,' Opt. Quant. Elect., vol. 33, pp. 327-341, 2001.

[9] W. M. Loh, S. E. Swirhun, T. A. Schreyer, R. M. Swanson, and K. C. Saraswat, "Modeling and measurement of contact resistances," IEEE Trans. Electron. Devices, vol. 34, pp. 512-523, 1987.

[10] A. Katz, P. M. Thomas, S. N. G. Chu, W. C. Dautremont-Smith, R. G. Sobers, and S. G. Napholtz, "Pt/Ti ohmic contact to $p^{++}$-InGaAsP $(1.3 \mu \mathrm{m})$ formed by rapid thermal processing," J. Appl. Phys., vol. 67, pp. 884-889, 1990. 